\title{
Effect of ozone treatment on the embryonic development of quail
}

\author{
O.K. Gogaev ${ }^{1,2}$, A.R. Demurova ${ }^{1}$, E.T. Choniashvili ${ }^{1}$
}

${ }^{1}$ Gorsky State Agrarian University, 362040, RNO-Alania, Vladikavkaz, Kirov Street, 37; ${ }^{2}$ North Caucasus Research Institute of Mining and Foothill Agriculture - a branch of the Federal State Budgetary Institution of Science of the Federal Scientific Center "Vladikavkaz Scientific Center of the Russian Academy of Sciences", 363110, RNOAlania, Prigorodny district, Mikhailovskoye village, Williams Street, 1.

Corresponding author e-mail: texmen2@ mail.ru;

Journal of Livestock Scienc (ISSN online 2277-6214) 12: 202-205

Received on 6/5/21, Accepted on 15/6/21, Published on 8/7/21

doi.10.33259/JLivestSci.2021.202-205

\begin{abstract}
Egg treatment with formaldehyde vapor is most often used in industrial poultry farming for preincubation, which has a toxic salt effect on the service staff and the development of embryos during incubation. In this regard, attention is paid to searching for environmentally friendly methods of processing eggs and stimulating embryos. The objective of the study is to determine the effect of preincubation egg treatment with ozone on embryo development. The research was carried out in MIP EcoDom LLC, which operates at the Gorsky State Agrarian University, from 2016 to 2019. For the study, Estonian quail eggs were taken, which were divided into four groups: the reference group was treated in the traditional way (formaldehyde vapor per $1 \mathrm{~m}^{3}$ of the volume of a special chamber of $35 \mathrm{ml}$ of $37 \%$ formalin solution plus $20 \mathrm{ml}$ of water plus $20 \mathrm{~g}$ of potassium permanganate); the first experimental group by ozonation for 10 minutes; the second experimental group - 20 minutes, and the third group - 30 minutes. The ozone concentration was $10 \mathrm{mg} / \mathrm{m}^{3}$. During the incubation process, biological control was carried out on the 5th, 10th, and 15th days of incubation, according to the established standards. Studies of the morphology of experimental birds showed that at the time of hatching, chicks of all experimental groups werewell developed. Based on the above, it can be concluded that ozonation of hatching eggs does not cause side effects and has a positive effect on the further development of chicks. It was found that the weight of quail embryos, incubated eggs, subjected to preincubation treatment with ozone lasting 20 minutes and a concentration of $10 \mathrm{mg} / \mathrm{m}^{3}$ was significantly higher than the same indicator in the reference for 6,10 and 15 day old chicks by $12.20 \%, 21.46 \%$, and $12.75 \%$, respectively. The same pattern is observed in terms of the embryo's length.
\end{abstract}

Keywords: embryo, mass, incubation, embryo length, development, Ozone treatment; Quail 


\section{Introduction}

Poultry farming is one of the most important branches of agriculture, which has made a huge contribution to ensuring food security of the Russian Federation and also other parts of world, as the main producer of meat (Angas et al 2018, Gogaev et al 2017, Kennedy et al 2017 and Oko et al 2016). Currently, the industry is considering expanding the range of products produced due to the wider use of different types of poultry. One of these species is the quail. According to a number of researchers, quail egg and meat products have high dietary qualities and are hypoallergenic (Gogaev et al, 2016a; Gogaev et al, 2016b; Gogaev et al, 2016c; Gogaev et al, 2017).

Particular attention should be paid to the period of embryonic development, which is associated with the incubation process to achieve high performance in poultry farming, and in particular, quail farming (Gogaev et al, 2019). Modern technologies promote the normal development of poultry embryos and pathogenic microflora during incubation and increase the microbial potential. Therefore, the main task of poultry farmers is the high-quality processing of hatching eggs and the equipment used during incubation (Gogaev et al, 2018).

Dorofeev and Khaustov attach a significant role to incubation in the technological chain of poultry production. The incubation technology should create optimal conditions for the development of embryos to increase young poultry's hatchability and survival rates(Afanas'evet al, 2016; Azarnova et al, 2010; Dobrenko et al, 2011;Dorofeyev et al, 2011;Fedotov et al, 2018). Therefore, poultry farmers are faced with finding new techniques that contribute to improving the incubation results and the quality of the resulting young birds.

From the analysis of the literature data in recent years, it follows that for a positive effect on poultry embryos, different methods of exposure are used: chemical, biological, and physical (Naydenskiyet al, 2007; Velichko et al, 2009;Gogaevet al, 2018). Egg treatment with formaldehyde vapor is most often used in industrial poultry farming for preincubation, which has a toxic salt effect on the service staff and the development of embryos during incubation.

In this regard, attention is paid to searching for environmentally friendly methods of processing eggs and stimulating embryos. Therefore, the search for promising environmentally safe methods of processing hatching eggs and stimulating embryos is relevant. The objective of the present study is to determine the effect of preincubation egg treatment with ozone on embryo development.

\section{Material and methods}

The research was carried out in MIP EcoDom LLC, which operates at the Gorsky State Agrarian University, from 2016 to 2019. For the experience, the household ozonator "Thunderstorm," developed by scientists of the Azov-Black Sea State Agricultural Engineering Academy, was used (Fig 1). For the study, Estonian quail eggs were taken, which were divided into four groups: the reference group was treated in the traditional way (formaldehyde vapor per $1 \mathrm{~m}^{3}$ of the volume of a special chamber of $35 \mathrm{ml}$ of $37 \%$ formalin solution plus $20 \mathrm{ml}$ of water plus $20 \mathrm{~g}$ of potassium permanganate); the first experimental group - by ozonation for 10 minutes; the second experimental group - 20 minutes, and the third group - 30 minutes. The ozone concentration was $10 \mathrm{mg} / \mathrm{m}^{3}$. According to the established standards during the incubation process, biological control was carried out on the 5th, 10th, and 15th days of incubation. To determine the parameters of morphogenesis after 6, 10, and 15 days, 5 embryos were taken from each group. They were left behind for 30 minutes. Then an autopsy was performed with eye scissors from the air chamber so that the path to the embryo was free. During the study of embryos, embryo length and weight were determined.The supernatant fluid was sucked out with a pipette; the yolk membrane was incised, the embryo membranes were opened in a Petri dish and measured with a ruler.

The indicators of the morphofunctional characteristics of the embryos are shown in Table 1. From the comparative analysis of the autopsy, visual examination, and weighing of quail embryos, it follows that the studied indicators have shifts in the experimental and reference groups.

Table 1 -Changes in morphofunctional characteristics of quail embryos

\begin{tabular}{|l|l|}
\hline Incubation days & \multicolumn{1}{|c|}{ Embryo development } \\
\hline Day 6 & $\begin{array}{l}\text { The head reaches a considerable size, the neck and trunk lengthen. There is a differentiation of the hand and } \\
\text { foot in the rudiments of the limbs. The intestinal wall is lengthened, a loop of the duodenum is formed, in } \\
\text { which the pancreas is marked. Due to the transition of water from the egg white, the yolk reaches the highest } \\
\text { mass. The first feathery papillae appear on the tail, back, and thighs. }\end{array}$ \\
\hline Day 10 & $\begin{array}{l}\text { An opening appears between the eyelids, and the scales on the legs are well defined. The } \\
\text { rudiments of feathers are visible along the back, tail, and around the acoustic foramen. }\end{array}$ \\
\hline Day 15 & $\begin{array}{l}\text { The yolk sac with its contents is almost completely retracted into the abdominal cavity. The } \\
\text { contents of the amniotic cavity disappear, the vessels of the allantois become desolate. The eyes } \\
\text { are slightly open. The head is located under the right-wing, the beak is directed towards the air } \\
\text { chamber. The beginning of breaking the shell. }\end{array}$ \\
\hline
\end{tabular}




\section{Results}

When incubating eggs, the embryo often lacks oxygen. Ozone breaks down into its atoms, which provides an optimal environment for the development of the embryo. Due to the intake of oxygen, the metabolism processes in the embryo are enhanced, its absorption increases by almost $40 \%$. Already on the 3rd day of incubation, the weight gain of the embryo is more intense. There is a noticeable increase in the absolute weight, stomach, heart, liver, and total weight of the embryo as a whole.

Exposure to ozone has a positive effect on respiratory metabolism, which is vital for releasing high-quality young animals. In the course of the study, it was found that the positive effect of ozone on the development of embryos wasmanifested to a greater extent at the end of the incubation period and to a lesser extent at the beginning.

From the data in Table 2, it can be seen that when laying eggs in all groups, the weight of the eggs was the same. Analyzing the egg weight loss by an incubation period, it can be noted that on the sixth day of incubation, this indicator ranged from $3.08 \%$ in the third experimental group to $3.42 \%$ in the reference group; the rest occupied an intermediate position. On the 10th day of incubation, these fluctuations were $6.67-7.26 \%$, and on the 15 th day $10.85-11.54 \%$. In all cases, the indicators of egg weight loss fit within the requirements.

Table 2 - Embryo mass and length dynamics

\begin{tabular}{|l|l|l|l|l|}
\hline \multirow{2}{*}{$\begin{array}{c}\text { Indicato } \\
\text { rs }\end{array}$} & \multicolumn{5}{|c|}{ Group } \\
\cline { 2 - 5 } & Reference & 1st group & 2nd group & 3rd group \\
\hline $\begin{array}{l}\text { At } \\
\text { laying }\end{array}$ & $11.70 \pm 0.14$ & $11.70 \pm 0.14$ & $11.70 \pm 0.14$ & $11.70 \pm 0.14$ \\
\hline 6 days & $11.30 \pm 0.04$ & $11.32 \pm 0.07$ & $11.34 \pm 0.06$ & $11.31 \pm 0.04$ \\
\hline 10 days & $10.85 \pm 0.03$ & $10.88 \pm 0.05$ & $10.92 \pm 0.04$ & $10.87 \pm 0.05$ \\
\hline 15 days & $10.35 \pm 0.04$ & $10.37 \pm 0.05$ & $10.43 \pm 0.04$ & $10.40 \pm 0.04$ \\
\hline Changes in embryo mass during incubation, g \\
\hline 6 days & $0.41 \pm 0.004$ & $0.44 \pm 0.003$ & $0.46 \pm 0.002$ & $0.44 \pm 0.002$ \\
\hline 10 days & $2.33 \pm 0.004$ & $2.65 \pm 0.004$ & $2.83 \pm 0.002$ & $2.69 \pm 0.006$ \\
\hline 15 days & $7.92 \pm 0.05$ & $8.25 \pm 0.01$ & $8.93 \pm 0.01$ & $8.86 \pm 0.01$ \\
\hline Changes in embryo length during incubation, mm \\
\hline 6 days & $17.7 \pm 0.02$ & $18.5 \pm 0.02$ & $19.8 \pm 0.02$ & $19.2 \pm 0.02$ \\
\hline 10 days & $37.8 \pm 0.02$ & $39.8 \pm 0.02$ & $41.6 \pm 0.02$ & $40.9 \pm 0.02$ \\
\hline 15 days & $52.1 \pm 0.02$ & $54.8 \pm 0.02$ & $56.3 \pm 0.02$ & $55.7 \pm 0.02$ \\
\hline
\end{tabular}

Analyzing the weight of embryos on day 6 of incubation, a positive effect on the development of the embryo treatment of eggs before incubation with ozone can be noted. At this age, the weight of the embryos of the first and third experimental groups was $0.44 \mathrm{~g}$, the second experimental group -0.46 , which is more than that of the embryos of the reference group by 7.32 and $12.20 \%$, respectively.

By the age of 10 days, the weight of quail embryos in relation to 6-month-olds increased in the reference group by 5.68 times; the first experimental group -6.02 ; the second experimental group -6.15 and the third -6.11 times. Consequently, at the age of 10 days, the weight of quail embryos of the second experimental group exceeded the same indicator of the reference group by $21.46 \%$; the first experimental group $-6.75 \%$ and the third experimental group $-5.2 \%$. In turn, according to this indicator, the embryos of the reference group were also inferior to the corresponding indicators of the first experimental group by 13.73 and the third experimental group $15.45 \%$.

By the age of 15 days, compared to the age of 10 days, the weight of quail embryos increased by 3.11-3.40 times. Although the largest relative increase occurred in the embryos of the reference group, it can be stated that at this age, the weight of the embryos of the experimental groups exceeded the same indicator of the embryos of the reference groups: in the first experimental group by $4.17 \%$; the second experimental group $-12.75(\mathrm{P} \geq 0.95)$, and the third experimental group $-11.87 \%(\mathrm{P} \geq 0.95)$.

At 6 days, the length of the quail embryo in the reference group was $17.7 \mathrm{~mm}$, in the first experimental group $-18.5 \mathrm{~mm}$, the second experimental group $-19.8 \mathrm{~mm}$, and the third experimental group $-19.2 \mathrm{~mm}$, which is more than in the reference group by $4.52,11.86$, and $8.47 \%$, respectively.

At 10 days, the length of the embryos increased by 2.10-2.15 times; that is, all groups had almost the same intensity of embryo growth in length. At this stage of embryonic development, the length of the embryos of the experimental groups subjected to ozonation before incubation was 5.29\% longer in the first experimental group; the second experimental group $-10.05 \%$, and the third experimental group $-8.20 \%$ compared to the same indicator of the reference group.

At 15 days, compared with 10 days, the length of quail embryos increased in the reference group by $37.83 \%$, in the first experimental group $-37.69^{\wedge}$; in the second experimental group $-35.34 \%$, and the third 
experimental group - 36.19\%. However, despite the lower indicators of the relative growth of embryos in length in the second experimental group, they were ahead of the other groups: the reference group by $8.06 \%$, the first experimental group $-2.74 \%$, and the third experimental group $-1.08 \%$.

\section{Conclusion}

Studies of the morphology of experimental birds showed that at the time of hatching, chicks of all experimental groups werewell developed. They hadwell-defined blood vessels, and the whole body wascovered with fluff. The limbs werepressed against the eggshell, and the head waslocated near the air chamber. No deviations from the norms and pathologies were found.

It was found that the weight of quail embryos, incubated eggs, subjected to preincubation treatment with ozone lasting 20 minutes and a concentration of $10 \mathrm{mg} / \mathrm{m}^{3}$, was significantly higher than the same indicator in the reference for6 -, 10- and 15-day-old chicks by $12.20 \%, 21.46 \%$, and $12.75 \%$, respectively. The same pattern wasobserved in terms of the embryo's length.

\section{References}

1) Afanas'ev, G. D., Popova L.A., Komarchev A.S., Saidu Suleiman Shehu. 2016. Marker Periods in Embryonic Development of Japanese Quails. Ptitsevodstvo - Poultry, iss. 6: 40-43.

2) Angas MR, Tabrizi HM, Pourelmi M, Abdollahi M, 2018. Effect of the Heracleum persicum and Echinacea angustifolia levels on performance in of male Japanese quail. Journal of Livestock Science 9: 96-100

3) Azarnova T.O., ZaytsevS.Yu., Naydenskiy M.S., AzarnovaL.Yu., PonomarovaYe.B. 2010. Using ribav and succinates to stimulate the natural resistance of chicken at different stages of ontogenesis.Doklady RASN, 1: 46-47.

4) Dobrenko A., Khvostorezov P. 2011. Pre-incubation treatment of poultry eggs in a constant magnetic field.Ptitsevodstvo. 3: 2-3.

5). Dorofeyev R.V., Khaustov V.N. 2011. Efficiency of the use of potassium permanganate in the process of incubation.Ptitsaiptitseprodukty. 6: 56-58.

6) Fedotov, D. N. et al. 2018. Embryonic develop-ment of quail. Scientific notes of the educational institu-tion of the Vitebsk Order Badge of Honor State Academy of Veterinary Medicine, 54(1): 76-81.

7) Gogaev O. K., Demurova A. R., Bideev B. A., Gutieva L. N. 2017. Characteristic of different breeds of quails. Scientific Life. 3: 54-65.

8) Gogaev O. K., Khasieva T. L., Dzeranova A. V., Demurova A. R. 2016a. The Influence of such Medications as "Protosubtilin GZH" and "Cellolux-F" on the Meat Productivity and Quality Indicators of Quail Meat. Scientific Life. 7: 88-97.

9) Gogaev, O. K., Khasieva, T. L., Demurova, A. R., Tokhtieva, L. Kh. 2019a. The ef-fectiveness of the integrated use of enzyme medication "Protosubtilin G3X" and "Cellolux-F" in quail breeding. Indo American Journal of Pharmaceutical Sciences, 6(5): 8948-8955.

10) Gogaev O. K., Khasieva T. L., Demurova A. R., Dzeranova A. V., Bestaeva R. D. 2016b. Effect of the complex usage of enzymatic preparations "ProtosubtilinGZkh" and "Tsellolyuks-F" in feeding on the egg productivity of egg-laying quails. Scientific Life. 9: 55-63.

11) Gogaev O.K., Bideev B.A., Demurova A.R., Gutieva L.N. 2016c. Comparative characteristics of quails' meat productivity. Proceedings of Gorsky State Agrarian University. 53: 25-30.

12) Gogaev, O. K., Abaev, A. A., Demurova, A. R., Choniashvili, E. T. 2019b. "Ecofriendly Method for Treatment of Hatching Eggs". International scientific and practical conference "AgroSMART - Smart solutions for agriculture", KnE Life Sciences. pp. 636-645.

13) Gogaev O. K., Chonishvili E. T., Bigeev B. A., Demurova A. R., Bestaev R. D., Dzeranova A. V. 2018. The Effect of Treatment of Hatching Eggs by ozone on Some Indices of Quails' Blood. Scientific life. 3: 75-82.

14) Kennedy O.O.O., Mbaba E.N., Iso I.E., Halilu A., Robert A.N., \& Micheal B. 2019. Effects of turmeric rhizome powder on growth, carcass and meat quality of Japanese quails fed sorghum-soybean-based diets. Journal of Livestock Science 11: 1-7.

15) Naydenskiy M.S., Nesterov V.V., LazarevaN.Yu. 2007. Ekologicheskibezopasnyyemetodypovysheniyavyvodakonditsionnykhtsyplyat [Ecologically safe methods for in-creasing the output of conditional chicken] // BIO. Oktyabr', Pp. 23-24.

16) Oko O.O.K., Asuquo O.R., Agiang E.A. and Osim E.E. 2016.Neuroendocrine and behavioural responses of Japanese quails to dietary Aspilia africana leaf meal and extracts. Journal of Livestock Science 8: 43-51

17) Velichko O., Cherepanov S. 2009. Actual research in the field of the extended use of poultry eggs components/Ptitsevodstvo, No. 11. Pp. 32-36. 